\title{
Understanding Ambivalent Sexism and its Relationship with Electoral Choice in Britain
}

\author{
Roosmarijn de Geus ${ }^{1 \star}$ (D), Elizabeth Ralph-Morrow ${ }^{2}$ (D) and Rosalind Shorrocks ${ }^{3}$ (D) \\ ${ }^{1}$ University of Reading, Reading, UK, ${ }^{2}$ King's College London, London, UK and ${ }^{3}$ University of Manchester, Manchester, UK \\ *Corresponding author. Email: r.a.degeus@reading.ac.uk
}

(Received 3 September 2020; revised 20 May 2021; accepted 20 October 2021; first published online 11 February 2022)

\begin{abstract}
We investigate the prevalence and correlates of sexism in the British political context, using a measure of ambivalent sexism that distinguishes between hostile and benevolent sexist attitudes. Drawing on original data from two nationally representative online surveys, we find that more than half of the population hold some sexist attitudes and that these are predicted by gender, education, religiosity and authoritarian values. We demonstrate that the most significant division in sexist attitudes within the British electorate falls along political rather than gender lines, with men and women expressing more similar views about sexism than either Conservative and Labour voters, or Leave and Remain supporters. We also find that endorsing hostile sexism is associated with voting Conservative in the 2019 general election, even after controlling for sociodemographic characteristics and political values. Our findings reveal that sexism is important for political competition in contexts where gender is not obviously salient.
\end{abstract}

Keywords: hostile sexism; benevolent sexism; voting behaviour; gender; British politics

Explicit support for gender equality in the UK is high. Recent surveys show that public endorsement of a traditional role for women in the home has declined, sexualised bullying online is widely condemned and most people think that it is wrong for a man to comment on a woman's appearance on the street (Phillips et al. 2018). Issues of gender equality and ideology are not significant elements of British political competition (Campbell 2016), and gender role ideology is not strongly associated with party support (Campbell and Shorrocks 2018). However, we argue that our understanding of gender attitudes in Britain and their association with political attitudes and behaviour is obscured by a lack of research on sexism. Sexism is a prejudice based on sex, usually against women, and sexist attitudes focus on feelings towards women (and men). We contend that investigating sexism can provide important evidence about the extent to which political divides are gendered in a context where gender issues are not a salient element of political discourse.

This article draws on original data in the form of two nationally representative surveys fielded before and after the UK's 2019 general election, incorporating items from the Ambivalent Sexism Inventory (ASI). The ASI was developed by psychologists (Glick and Fiske 1996) to measure sexism and has recently been used by political scientists to understand Trump's 2016 election victory (Bock, Byrd-Craven and Burkley 2017; Cassese and Barnes 2019; Frasure-Yokley 2018). Glick and Fiske conceptualise sexism as comprising two dimensions: hostile and benevolent. Hostile sexism justifies male power through a derogatory characterisation of women. Benevolent sexism is subjectively favourable towards women but is ultimately disempowering, as it idealises women as wives, mothers and romantic love objects. Our study represents the 
first use of the ASI within a nationally representative sample in the UK and only the second study within political science to have fielded both benevolent and hostile sexism questions to a nationally representative sample (see also Winter 2018). It is also the first study to provide results from two such surveys, allowing us to comment on the robustness of our findings and reflect on the sensitivity of the ASI scale to the inclusion of specific items and the use of a 'don't know' response option.

We show that more than half of the population hold sexist attitudes. Sexism is associated with authoritarian values, supporting Leave in the 2016 European Union (EU) referendum and voting Conservative in the 2019 general election. These associations remain after controlling for other sociodemographic characteristics and, in the case of the relationship between hostile sexism and Conservative vote choice, other political values. The differences in sexism between political groupings are larger than the differences in sexism between men and women. Our study therefore shows that sexism generally, and hostile sexism in particular, are important features of Britain's political landscape.

We make four key contributions to understanding the relationship between gender attitudes and political cleavages and competition. First, we offer the first overview of the prevalence of hostile and benevolent sexist attitudes using the ASI in the UK. This also provides important comparative data to existing United States-based studies. Secondly, we find a relationship between hostile sexism and electoral choice in a context where gender is not obviously politically salient. Previous research has identified an association between hostile sexism and voting for Trump in the 2016 US presidential election, but our findings indicate that sexism is associated with right-wing and/or conservative electoral options in general, rather than specifically with Trump support. We suggest that sexists perceive these options as upholding traditional hierarchies of gender and contend that political parties that are perceived as feminine may be rejected by hostile sexist voters. Thirdly, we show that key British political divides - EU referendum vote choice and party support - have a gendered dimension to them. Sexism divides the British electorate in ways that are associated with existing dimensions of political competition, which has implications for the ways in which parties might attempt to motivate supporters and for the priorities of those supporters. The close association between sexism and party support shows that although gender issues might not hold great salience in party competition now, they nevertheless could become an important dimension of contestation in the future. Fourthly, we provide several insights into the measurement of ambivalent sexism, shedding light on a tool that is increasingly used by scholars in diverse disciplines. Our study is able to compare two separate surveys that include ASI items and share many commonalities, yet differ in the number of items included and the provision of a 'don't know' response option. We particularly find that the results for benevolent sexism are inconsistent, reflecting the more mixed findings on the importance of benevolent sexism in current US literature (Bock, Byrd-Craven and Burkley 2017; Ratliff et al. 2017; Winter 2018) and suggesting that research findings of benevolent sexism are more sensitive to the particular selection of ASI items.

\section{Sexism Scholarship}

\section{Ambivalent Sexism}

Modern scholarly understandings of prejudice are typically grounded in Allport's $(1954,9)$ canonical definition of ethnic prejudice as 'an antipathy based upon a faulty and inflexible generalisation'. While ethnic prejudice may be uniformly hostile, gendered prejudice is not (Winter 2018). As Burns and Gallagher $(2010,430)$ observe, unlike racial inequalities, which are often entrenched by segregation, gender inequality involves 'role segregation mixed with intimacy.... Gender is a hierarchy we often perpetuate in our families, with people we love.' This feature of gender relations means that sexism - or sex-based prejudice - can encompass both antipathy and subjectively positive views that nevertheless perpetuate inequality. 
To reveal the multidimensional nature of sexism, psychologists Glick and Fiske $(1996,491)$ designed the ASI, a 22-item test that measures both hostile and benevolent sexism. Hostile sexism is an attitude that conforms to Allport's (1954) definition and involves 'antipathy toward women who are viewed as usurping men's power' (Glick and Fiske 2001, 109). It is measured on the ASI with items such as 'Women seek to gain power by getting control over men' (Glick and Fiske 1996, 512). Benevolent sexism refers to subjectively positive but ultimately disempowering beliefs about women and is characterised by a reverence for women in the roles of wives, mothers and romantic love objects (Glick and Fiske 1996). It is measured by statements such as 'Women should be cherished and protected by men' (Glick and Fiske 1996, 512). Although the word 'benevolent' has positive connotations, Glick and Fiske (1996) make clear that benevolent sexism should be understood as conveying a combination of dominance and paternalism. There are three components to benevolent sexism: protective paternalism, whereby women are dependent on men as protectors and providers; complementary gender differentiation, reflecting a belief that women and their traits complement and complete men; and heterosexual intimacy, referring to men's desire for sexual and psychological closeness with women. As Glick and Fiske $(1996,492)$ observe, both hostile and benevolent sexism view women as "the "weaker" sex ... and ... serve to justify men's structural power'. For a discussion of how the ASI compares to other measures of gender attitudes, see the Online Supplementary Material.

\section{Who Is Sexist?}

Glick and Fiske's (1996) initial research showed that men score higher on the ASI than women, particularly for hostile sexism. In a subsequent cross-national study, Glick et al. (2000) found that, relative to men, women disavow hostile sexism but often endorse benevolent sexism. The authors observed that this tendency was strongest in sexist cultures, where women may potentially need the protection and idealisation associated with benevolent sexism in order to avoid hostility. In contrast, in egalitarian societies, women may reject benevolent sexism because they are less dependent on men and unlikely to incur sexist hostility if they refuse to adhere to conventional gender roles. Since Britain is relatively egalitarian, we expect women to have lower scores for both hostile and benevolent sexism than men.

Other studies suggest that education and age are associated with sexism. Those with lower levels of education tend to score high on hostile and benevolent sexism scales (Glick, Lameiras and Castro 2002; Schaffner, Macwilliams and Nteta 2018). Hellmer, Stenson and Jylhä (2018) hypothesised that this could be due to exposure to discussions about sexism and gender inequality at universities and workplaces that require higher education. However, it could also be that less sexist individuals are more likely to pursue higher education or that unmeasured variables such as class explain the relationship.

The relationship between sexism and age is inconsistent, though the evidence broadly suggests older people are more sexist than younger people. Glick, Lameiras and Castro (2002) found that age was associated with more benevolent, but not hostile, sexism and suggest that this could be explained by preferences for maintaining the status quo increasing with age or by cohort differences. By contrast, Gaunt (2012) found that age had a weak and inconsistent effect, with older men and women being less likely to express hostile sexist beliefs but older women being more likely to endorse benevolent sexism. Garaigordobil and Aliri (2013) observe that sexism increases with age, but not in a linear fashion. The authors found that respondents aged 14-18 had high ambivalent sexism scores that then decreased until the age of 54 before increasing again, and they speculated that young people initially adopt sexist attitudes partially because of behaviour modelled in video games and pornography (Garaigordobil and Aliri 2013).

Research has established a relationship between benevolent sexism and religiosity (Burns and Busso 2005). Burns and Busso (2005) point to the benevolent justification of men's greater power and status compared to women in many religions: religious fundamentalisms express respect for 
the family and child rearing, and Bible passages evoke protective paternalism. Glick, Lameiras and Castro (2002) similarly found that Catholic religiosity predicted benevolent, but not hostile, sexism and suggested that the modern Catholic Church justifies conventional gender roles through the promotion of benevolent sexism, such as male priests assuming responsibility for the care and protection of the Church.

Studies have found correlations between authoritarianism and ambivalent sexism. Right-wing authoritarianism, often measured by the Right-Wing Authoritarianism (RWA) scale, encompasses three dimensions: (1) authoritarian submission/conservatism, prioritising respect for authority, social order and defence of the status quo; (2) authoritarian aggression/authoritarianism, a motivation to punish those who transgress established societal norms and conventions; and (3) conventionalism/traditionalism, including respect for traditional norms and values (Altemeyer 1981; Duckitt et al. 2010). Holding an authoritarian world view should correlate with both hostile and benevolent sexism. Hostile sexism encompasses resentment against women who challenge patriarchal structures and norms, and should thus appeal to authoritarians who want to coercively maintain social structures. Benevolent sexism includes an adherence to traditional ideas of gender complementarity, male dominance and female fragility, and should therefore attract authoritarians who are motivated to uphold traditional values and ways of life. While some empirical research has found authoritarianism, measured using RWA, to be primarily associated with benevolent sexism (Christopher and Mull 2006; Sibley, Wilson and Duckitt 2007), others have also found a strong positive relationship between RWA and hostile sexism (Austin and Jackson 2019; Hellmer, Stenson and Jylhä 2018).

This leads to our first hypothesis:

Hypothesis 1 (H1): Sexist attitudes will be highest among men, older age groups, those with lower levels of education, those who are more religious and those who are more authoritarian.

\section{Sexism and Political Attitudes and Behaviours}

Understanding sexism, and antipathy towards women specifically, is important because hostile sexism has been shown to influence political attitudes and behaviour. Cassese and Barnes $(2019,692)$, drawing on two hostile sexism items included in the American National Election Study, found that white women who endorse hostile sexism were more likely to support Trump in 2016, even after 'controlling for education, ideology, partisanship, core values, racial resentment, and authoritarianism'. The authors observe that sexism and denying discrimination against women were strong predictors of white women's vote in 2016 but not of Romney support in 2012; this may be due to the salience of sexism in the 2016 campaign, having been generated by Clinton's historic candidacy and Trump's anti-woman behaviour and remarks. Cassese and Barnes (2019) suggest that white women might endorse sexist beliefs and power arrangements in order to protect the privileged status of white men, on whom they may be economically dependent, and thereby maintain their higher status vis-à-vis minority ethnic women. Schaffner, Macwilliams and Nteta (2018) similarly used four hostile sexism indicators in the nationally representative Cooperative Congressional Election Study and found that moving from the least to the most sexist end of the scale was associated with a 20-point increase in Trump support. Like Cassese and Barnes (2019), Schaffner, Macwilliams and Nteta (2018) note that the effects of hostile sexism were more potent in 2016 than 2012.

While hostile sexism has been shown to be predictive of Trump support, the relationship between benevolent sexism and voting behaviour is less clear. Bock, Byrd-Craven and Burkley's (2017) study of undergraduate students examined hostile and benevolent attitudes and found that only the former predicted Trump support. The authors observe that benevolent sexism rewards women who adhere to conventional gender roles, while hostile sexism punishes women who deviate from traditional norms; as an agentic woman seeking a leadership position, 
Clinton 'represented the quintessential backlash candidate' (Bock, Byrd-Craven and Burkley 2017, 192). Ratliff et al. 2017 study, administered to Project Implicit volunteer respondents, similarly concluded that hostile, but not benevolent, sexism predicted Trump support, controlling for political ideology, gender and attitudes towards minorities. Ratliff et al. 2017 speculate that hostile sexism could be associated with negative attitudes towards Clinton because of her disruption of the status quo in seeking a leadership role, as well as positive attitudes towards Trump due to his offensive statements directed at women.

However, drawing on nationally representative survey data, Winter (2018) found that voters high in hostile and benevolent sexism were more likely to support Trump over Clinton, yet benevolent sexism was irrelevant for voter choice at the congressional level. To understand this result, Winter (2018) conducted a conjoint experiment where candidate sex and gendered style (for example, collaborative and cooperative or decisive and forceful) were randomly assigned. This experiment revealed that benevolent sexists opposed candidates with feminine styles and supported candidates with masculine styles, regardless of the candidate's sex. Winter (2018) concludes that hostile sexists are resistant to female leadership, while benevolent sexists reject symbolically feminine leadership and may be particularly sensitive to role congruity.

The studies discussed earlier were all conducted in the United States, where questions of gender ideology are, and have historically been, particularly salient (Campbell 2016). The theoretical link between sexism and electoral choice is also sometimes unclear. Many studies conclude that there was something particular about the 2016 presidential election: the first female presidential nominee from a major party (Clinton) as opposed to an openly sexist male candidate (Trump). Schaffner (2022) finds a strengthened relationship between hostile sexism and vote choice in the 2018 midterms, but this also cannot be separated from the Trump presidency. An alternative explanation is that sexists prefer conservative candidates in general, rather than Trump in particular, because they are seen as upholding traditional gender roles. Conversely, non-sexists might prefer left-wing candidates because they are more likely to emphasise women's rights. The literature therefore presents a convincing case that hostile - and perhaps benevolent sexism was associated with Trump support in 2016, but more research is needed to test whether similar associations hold in other contexts.

Furthermore, the existing research contains methodological and measurement limitations. With the exception of Winter (2018), none of these studies use a nationally representative sample to measure both hostile and benevolent sexism. Studies that do draw on nationally representative samples only measure hostile sexism (Cassese and Barnes 2019; Schaffner, Macwilliams and Nteta 2018), whereas other studies that examine both hostile and benevolent sexism draw on university students and volunteers (Bock, Byrd-Craven and Burkley 2017; Ratliff et al. 2017). It is unclear, therefore, whether the benevolent sexism findings will hold in a representative sample. We thus need to investigate sexism and its association with political attitudes and behaviour in other environments using nationally representative survey data. Britain provides an excellent context, as gender has tended to be less politically salient than in the United States but comparisons have been made between Trump's election and the success of the Leave side in the 2016 EU referendum (see, for example, Inglehart and Norris 2017).

We anticipate that sexists should be more likely to have voted Leave in the EU referendum. In the context of US politics, Deckman and Cassese $(2019,6)$ use the idea of gendered nationalism that is, the belief that the United States has grown 'too soft and feminine' - to argue that gendered beliefs exert an important influence on political behaviour. They found that voters who endorse gendered nationalism were more likely to support Trump, possibly because the overt masculinity of his campaign resonated among those who were concerned that the nation was becoming too weak. Brexit rhetoric arguably contained similarly masculine appeals, with such key Leave campaigners as Boris Johnson (2016) claiming that 'the public can see all too plainly the impotence of their own elected politicians' in the face of EU regulation and Michael Gove (2016) asserting that 'Britain would be stronger outside of the EU', while rhetorically asking 'are we really too small, 
too weak and too powerless to make a success of self-rule?'. That the idea of control formed a key part of the Brexit campaign - as evidenced by its slogan 'Take Back Control' - is also notable given that the gender studies literature indicates that exerting control is a key feature of masculinity (Schrock and Schwalbe 2009). It is therefore possible that Leave campaign language propagated a masculine-coded view of both Brexit and the state, thus issuing a latent appeal to sexist voters. Additionally, Green and Shorrocks (2021) found that men who perceived men to be discriminated against were more likely to vote Leave, even after controlling for sociodemographic characteristics and values.

We also expect sexists to be more likely to have voted Conservative in the 2019 general election. This is both because of the strong connection between voting Leave in 2016 and voting Conservative in 2019 (Prosser 2020), and the expectation that those who hold sexist attitudes might vote for conservative candidates and parties because of their association with traditional hierarchies and lifestyles. Additionally, research suggests that voters may ascribe a masculine or feminine gender identity to political parties. Winter's (2010) study found that US voters were more likely to associate stereotypically masculine traits, such as strength and self-confidence, with the Republican Party, and stereotypically feminine traits, such as kindness and care, with the Democratic Party. These associations may arise because of party 'ownership' of certain issues (whereby Republicans are viewed as better at handling defence and crime, and Democrats are seen as stronger on education and healthcare) and the relative visibility of women within the Democratic Party (Winter 2010). Within Britain, similar dynamics are at play: over 50 per cent of Labour Party MPs are women, and voters view the party as better able to handle healthcare, whereas the Conservatives are seen as more competent on defence and security (YouGov 2019). These perceptions might lead sexists to disdain the Labour Party and support the Conservatives.

Although the association between benevolent sexism and political behaviour has been less strong in some work (Bock, Byrd-Craven and Burkley 2017; Ratliff et al. 2017), Winter's (2018) use of the ASI in a nationally representative survey found an association between both hostile and benevolent sexism and Trump support; as such, we hypothesise that both hostile and benevolent sexism will be associated with Leave/Conservative voting. It is important to note that although we expect to find associations between sexism and Leave and Conservative voting, we are not attempting to demonstrate causal relationships. ${ }^{1}$ However, we do expect these relationships to hold, even after controlling for confounding factors, such as age, education and political values. Therefore, our remaining hypotheses are:

Hypothesis 2 (H2): Hostile and benevolent sexists will be more likely to have supported Leave than Remain in the EU referendum.

Hypothesis 3 (H3): Hostile and benevolent sexists will be more likely to have voted Conservative than Labour in the 2019 general election.

\section{Methodology}

\section{Data}

We embedded ambivalent sexism questions in two surveys. The first survey was fielded to 1,611 respondents just prior to the UK general election in December 2019, with funding from the Elections, Public Opinion and Parties (EPOP) section of the Political Studies Association, and is hereafter referred to as the EPOP survey. The second survey is the British Elections Study

\footnotetext{
${ }^{1}$ Given the observational nature of our data, we do not seek to make causal claims about the association between sexist attitudes and vote choice. In our view, sexism is an attitude and, as such, sequentially follows sociodemographic features, such as age or gender, but precedes party attachments and voting behaviour. However, in this piece, we are not able to empirically establish this sequence.
} 
Internet Panel (BESIP) (Fieldhouse et al. 2020). Our questions were part of Wave 19, conducted in January 2020, just after the election. Approximately 8,000 BESIP respondents completed the ambivalent sexism module, though much of our analysis is conducted on a subset of these respondents due to missing values on other variables. Both surveys were conducted online by YouGov and were weighted to be representative of the British adult population on key demographics. Conducting two surveys using the ambivalent sexism items is a valuable contribution. As these questions have not been fielded to nationally representative samples in Britain before, our approach allows us to test the sensitivity of the scales and consistency of results across different samples, scale constructions and response categories. This is important, as political scientists increasingly use the ASI to understand political behaviour and attitudes.

We included four ambivalent sexism items in the EPOP survey and six items in the BESIP (see Table 1). Due to space and time constraints in these surveys, it was not possible to run the full 22-item ASI. The items were selected because they are comparable to those included in US studies of sexism and political behaviour that use a subset of these items (Cassese and Barnes 2019; Cassese and Holman 2019; Frasure-Yokley 2018; Schaffner, Macwilliams and Nteta 2018). When it comes to hostile sexism, these are three out of the six items that contribute the most to the latent concept, and the correlation between these items and the full 22-item scale is very strong (Schaffner 2021), suggesting that we do not lose much by restricting the items we use. To our knowledge, a similar study investigating reduced surveys for benevolent sexism is not available, and so we are more reliant here on our own judgement of which items are particularly representative of the concept and the items that have been used in studies in the United States. We discuss the measurement of benevolent sexism in our conclusion.

In both surveys, respondents could agree or disagree with the statements using a five-point scale that ranged from 'agree strongly' to 'disagree strongly', with a midpoint of 'neither agree nor disagree'. In the BESIP, respondents had a 'don't know' option. We provide an overview of the percentage of 'don't know' responses to the BESIP items in the Online Supplementary Material. Most items received less than 5 per cent of 'don't know' responses, but 9 per cent of respondents chose 'don't know' for the benevolent sexism 'purity' item. For the remainder of the analyses, we exclude the 'don't know' responses from the BESIP data.

Due to space considerations, the analyses that follow mostly use the BESIP data, which include more demographic and attitudinal variables than the EPOP data and hence allow us to present more complete models of political behaviour. We replicate our analysis using the EPOP data in the Online Supplementary Materials and discuss any relevant differences between the two data sets in the text.

\section{Hostile and Benevolent Sexism Scales}

We first examined the correlations between the hostile and benevolent sexism items. Using the BESIP data, we find that the Cronbach's alpha is 0.77 for the hostile items and 0.67 for the benevolent items. This was 0.71 and 0.52 , respectively, in the EPOP survey, which only used two items each for hostile and benevolent sexism. Glick and Fiske (1996; Glick and Fiske 2001) previously noted the higher internal consistency of the hostile sexism index in comparison to the benevolent sexism index and suggest that this reflects the multidimensionality of benevolent sexism (see earlier). We cannot comprehensively address this multidimensionality with our limited question items that capture only two out of the three dimensions (protective paternalism and complementary gender differentiation). However, our lower consistency scores for benevolent sexism are in line with what would be expected for this index.

All six items combined have a Cronbach's alpha of 0.83 , but we analyse hostile and benevolent sexism separately. The two dimensions of sexism are conceptually different. Moreover, they have been found to load onto two factors (Glick and Fiske 1996; Glick and Fiske 1997; Schaffner 2021), which we replicated in both surveys through exploratory factor analysis. The correlation between 
Table 1. Ambivalent sexism items included in EPOP and BESIP surveys

\begin{tabular}{llc}
\hline & EPOP & BESIP \\
\hline Hostile sexism items & & \\
Women seek to gain power by getting control over men & $X$ & $X$ \\
Most women interpret innocent remarks or acts as being sexist & & $X$ \\
Most women fail to appreciate fully all that men do for them & $X$ & $X$ \\
Benevolent sexism items & $X$ & $X$ \\
Women should be cherished and protected by men & $X$ \\
Many women have a quality of purity that few men possess & \\
A good woman should be set on a pedestal by her man & \\
\hline
\end{tabular}

the separate hostile and benevolent sexism scales (0.36) is also not high. To create hostile and benevolent scales, we simply sum a respondent's answers across all three items. The scales have been coded to range from -1 to +1 on a continuous scale, where negative values indicate disagreement with the statement (low sexism levels) and positive values indicate agreement with the statement (high sexism levels).

In the following analysis, we describe the extent of the British population's hostile and benevolent sexist attitudes; investigate these attitudes' key predictors; and analyse the extent of sexism's association with EU referendum and 2019 general election vote choices.

\section{Analysis}

\section{Does the British Electorate Hold Sexist Attitudes?}

Figure 1 shows the distribution of the hostile and benevolent sexism scales in the BESIP. Positive values reflect higher levels of sexism. Both the hostile and benevolent distributions are left-skewed towards the non-sexist end of the scale and peak at the midpoint ( 0$)$ of the scales, with approximately 20 per cent of respondents at this midpoint. Approximately 30 per cent of respondents fall on the sexist end of the hostile sexism scale and 35 per cent of respondents fall on the sexist end of the benevolent sexism scale. The Online Supplementary Materials provide these distributions for the EPOP survey, where the proportion of respondents at the midpoint is somewhat higher: 25 per cent for the hostile scale and 30 per cent for the benevolent scale. In the EPOP data, we find a similar percentage of respondents at the sexist end of the benevolent scale ( 35 per cent) but a much higher percentage on the sexist end of the hostile scale ( 42 per cent).

This difference could be related to the absence of a 'don't know' option in the EPOP survey and explain the higher proportion of respondents who opted for the midpoint in this survey. It could also be the case that a 'don't know' option is perceived as a more socially desirable answer to someone who would otherwise answer at the sexist end of the scale, thereby reducing the prevalence of sexism in the BESIP data. This could especially be the case for hostile sexism. The level of sexism we find for our British samples is lower than that found in the United States, where Edwards and Schaffner (2020) find that nearly half of American respondents in 2019 were on the hostile end of the scale, and around 60 per cent fell on the benevolent end of the scale.

We further examine the percentage of respondents that are sexist on both scales and which percentage hold exclusively hostile (but not benevolent) attitudes, and vice versa. To do so, we divide the sample into three categories: those who score a total of 0 (the midpoint) are considered 'neutral'; those who scored above 0 are considered sexist on the particular indicator (hostile or benevolent); and those who score below 0 are considered non-sexist on that indicator.

The percentages of respondents in each category are shown in Table 2. A total of 26 per cent of respondents are not sexist on either indicator. This non-sexist group is majority female (65 per cent), Labour voting (47 per cent) and Remain voting (69 per cent); the mean age of this group is 

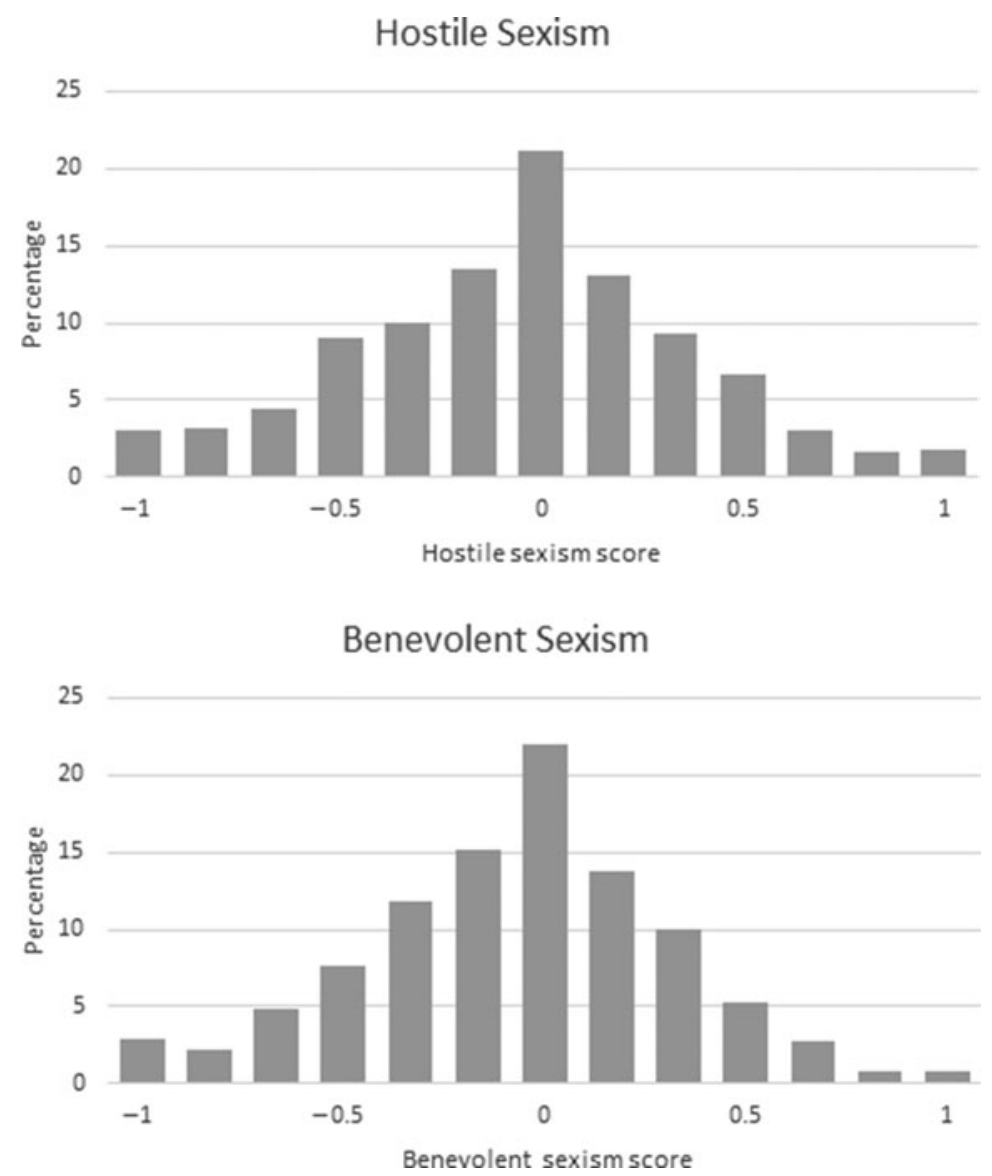

Fig. 1. Distributions of hostile and benevolent sexism in BESIP. Notes: $N=7,752$ for hostile sexism and $N=7,799$ for benevolent sexism. Data are weighted.

Benevolent sexism score

46. A total of 17 per cent of respondents are sexist on both the hostile and benevolent scales. ${ }^{2}$ This group is majority male (64 per cent), Conservative voting (57 per cent) and Leave voting (70 per cent); the mean age of this group is 50 . More than half the sample (53 per cent) holds sexist attitudes in some way or another - either hostile or benevolent, or both. A total of 12 per cent hold hostile but not benevolent views, whereas 11 per cent hold benevolent but not hostile views.

The results are broadly the same in the EPOP data, with a slightly higher proportion again holding either or both types of sexist attitudes (60 per cent). We conclude that sexist attitudes are prevalent among the British population. In both surveys, more than half of respondents hold some sexist attitudes and almost 20 per cent hold both hostile and benevolent sexist attitudes.

We now look at the mean difference in sexism scores for the entire sample, as well as for key groups: men v. women, Labour v. Conservative voters and Leave v. Remain voters. The differences are calculated using bivariate ordinary least squares (OLS) regressions, and the coefficients in Table 3 show the difference in the mean sexism scores between the various groups. We find that women are significantly less likely to hold hostile sexist attitudes than men and that Conservative voters and Leave voters are significantly more likely to hold hostile sexist attitudes than Labour voters and Remain voters. We also find statistically significant gaps between political groupings for benevolent sexism, though they are much smaller in magnitude. The EPOP data

\footnotetext{
${ }^{2}$ Again, this is lower than the 32 per cent of Americans that Edwards and Schaffner (2020) identify as having both hostile and benevolent sexist views.
} 
Table 2. Intersection of hostile and benevolent sexist attitudes in UK

\begin{tabular}{lccr}
\hline & & \multicolumn{2}{c}{ Hostile sexism } \\
\cline { 2 - 4 } Benevolent sexism & Not sexist (\%) & Neutral (\%) & Sexist (\%) \\
\hline Not sexist & 26 & 6 & 12 \\
Neutral & 6 & 9 & 7 \\
Sexist & 11 & 6 & 17 \\
\hline
\end{tabular}

Notes: Data are weighted. $N=7,714$.

Table 3. Sexist attitudes by gender and political grouping

\begin{tabular}{lrr}
\hline & Hostile sexism & Benevolent sexism \\
\hline Women v. men & $-0.18^{\star \star \star}(0.01)$ & $-0.10^{\star \star \star}(0.01)$ \\
Conservative v. Labour & $0.27^{\star \star \star}(0.02)$ & $0.13^{\star \star \star}(0.02)$ \\
Leave v. Remain & $0.24^{\star \star \star}(0.01)$ & $0.17^{\star \star \star}(0.01)$ \\
\hline
\end{tabular}

Notes: Estimates are obtained using bivariate OLS regression models with survey weights. Coefficients represent the difference in means between the various groups (men/women, Conservative/Labour and Leave/Remain). Sexism scales range from -1 to +1 . Standard errors are in parentheses. ${ }^{* \star *} \mathrm{p}<0.001 ;{ }^{* *} \mathrm{p}<0.01 ;{ }^{*} \mathrm{p}<0.05$.

show the same patterns, except the difference between men and women on the benevolent indicator is not statistically significant.

In both surveys, we find that the size of the gap between men and women is substantively smaller than the gap between Conservative and Labour voters and the gap between Leave and Remain voters. This accords with US research, which finds that divisions in sexist attitudes are more likely to be found along political rather than gender lines (Ratliff et al. 2017). There is more agreement about sexism between men and women than there is between Conservative and Labour voters and between Leave and Remain supporters in Britain.

\section{What Predicts Sexist Attitudes in the British Electorate?}

We now investigate the sociodemographic and attitudinal variables associated with sexism in Britain. H1 expected that male, older, less educated, more religious and more authoritarian people would score higher on the sexism scales. To test this, we first run OLS regression models with the hostile and benevolent sexism scales as dependent variables. Our key predictors include gender, age, education and religion, with additional controls for occupational class, employment status and marital status. We then run a second model where we add libertarian-authoritarian values as well as the left-right ideological placement scales. With regards to measuring authoritarianism, there is no RWA scale in the BESIP. However, the authoritarian-libertarian scale we used includes items that are very similar to some of the RWA items, especially those used in reduced RWA scales (see, for example, Bizumic and Duckitt 2018), and tap into the three facets of authoritarianism described earlier. For example, the authoritarian-libertarian scale includes items such as: 'Young people today don't have enough respect for traditional British values' (measuring traditionalism); 'People who break the law should be given stiffer sentences' (measuring authoritarianism); and 'Schools should teach children to obey authority' (measuring conservatism). This authoritarian-libertarian scale is also used extensively in studies of British political behaviour and has become increasingly predictive of this behaviour in recent years (Fieldhouse et al. 2019).

Figures $2 \mathrm{a}$ and $2 \mathrm{~b}$ plot the coefficients from the multivariate models for the BESIP. We find clear and consistent results for gender, religion, education and political values. As expected, women score lower for both hostile and benevolent sexism, even after controlling for sociodemographic and attitudinal variables. We replicate this finding with the EPOP survey for hostile but 


\section{Hostile Sexism}
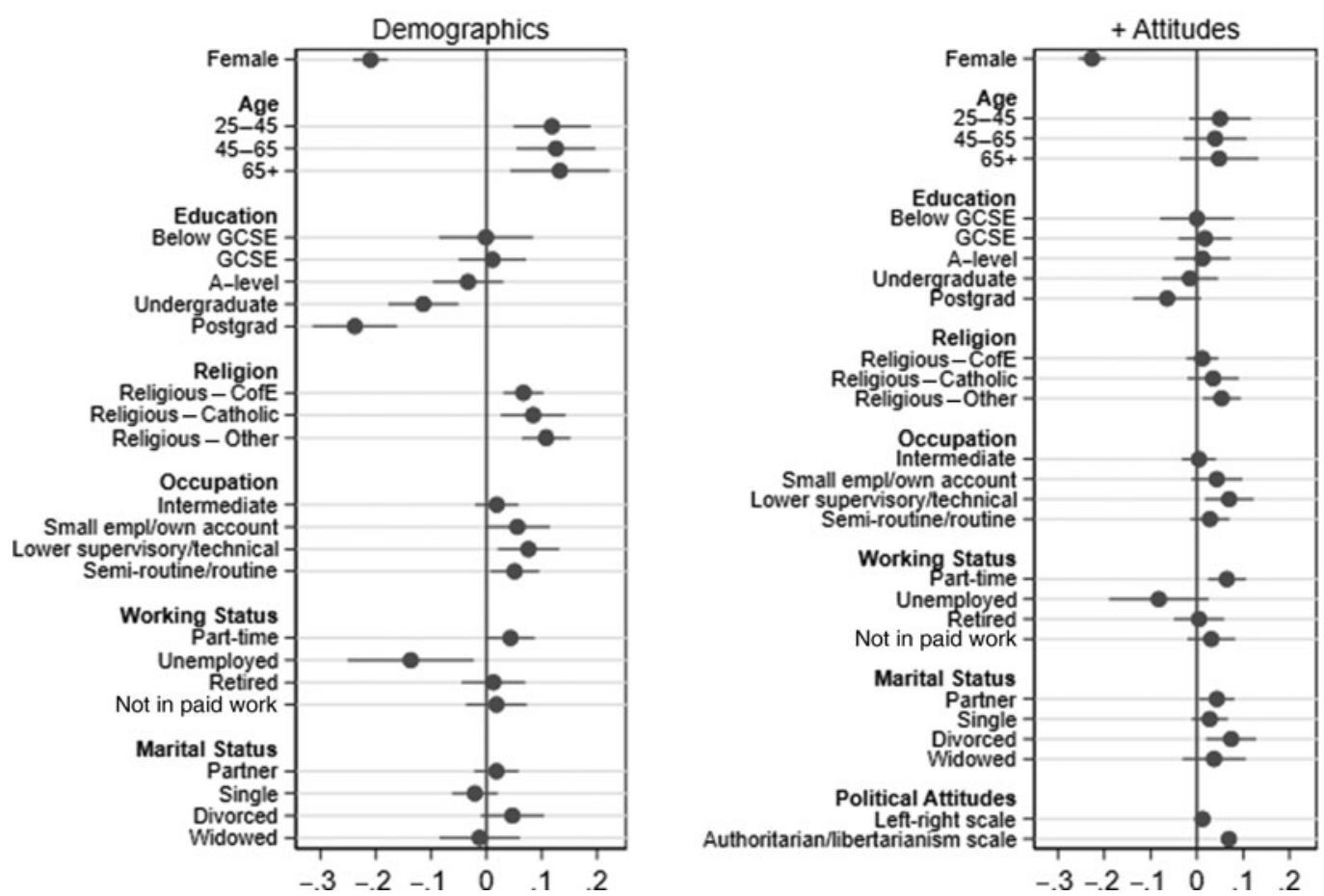

Fig. 2a. Coefficient plots from OLS regression predicting hostile sexism (BESIP).

Notes: $N=3,096$. Data are weighted, coefficients are unstandardised and 95 per cent confidence intervals are shown.

not benevolent sexism, which suggests that gender differences might be more robust for the hostile indicator. We note however that in the EPOP data, we do not have the ability to control for religion, nor are we able to control for left-right position or authoritarianism (see Part B of the Online Supplementary Materials).

When it comes to age, our descriptive results suggest that it is the 18- to 25-year-olds that are particularly non-sexist, especially for hostile sexism, ${ }^{3}$ though this is no longer significant once we control for political values, suggesting that the differences are reflective of age-based value differences (Shorrocks 2018). In line with H1, there is a negative association between higher education and both hostile and benevolent sexism (also replicated in the EPOP survey). University-level education (undergraduate or postgraduate) is particularly significant. This educational gradient, however, disappears once we include left-right and authoritarian-libertarian values, suggesting that the educational divide is a value divide. We also find that those who identify as religious are more sexist (both hostile and benevolent) than those without a religion. This is true for both those who belong to the Church of England, Catholics and those belonging to another religion. The association between religiosity and sexism remains statistically significant once value indicators are included for benevolent, but not hostile, sexism, suggesting that for hostile sexism, some of the association between religion and sexism is mediated by values (see also Burn and Busso 2005).

Authoritarianism is positively correlated with sexism. The relationship is of a similar magnitude for both hostile and benevolent sexism. This is in line with the theoretical expectation that sexist attitudes are held by authoritarians because of their desire to maintain traditional values

\footnotetext{
${ }^{3}$ Hostile and benevolent distribution graphs for the four age groups are available in the Online Supplementary Materials.
} 


\section{Benevolent Sexism}
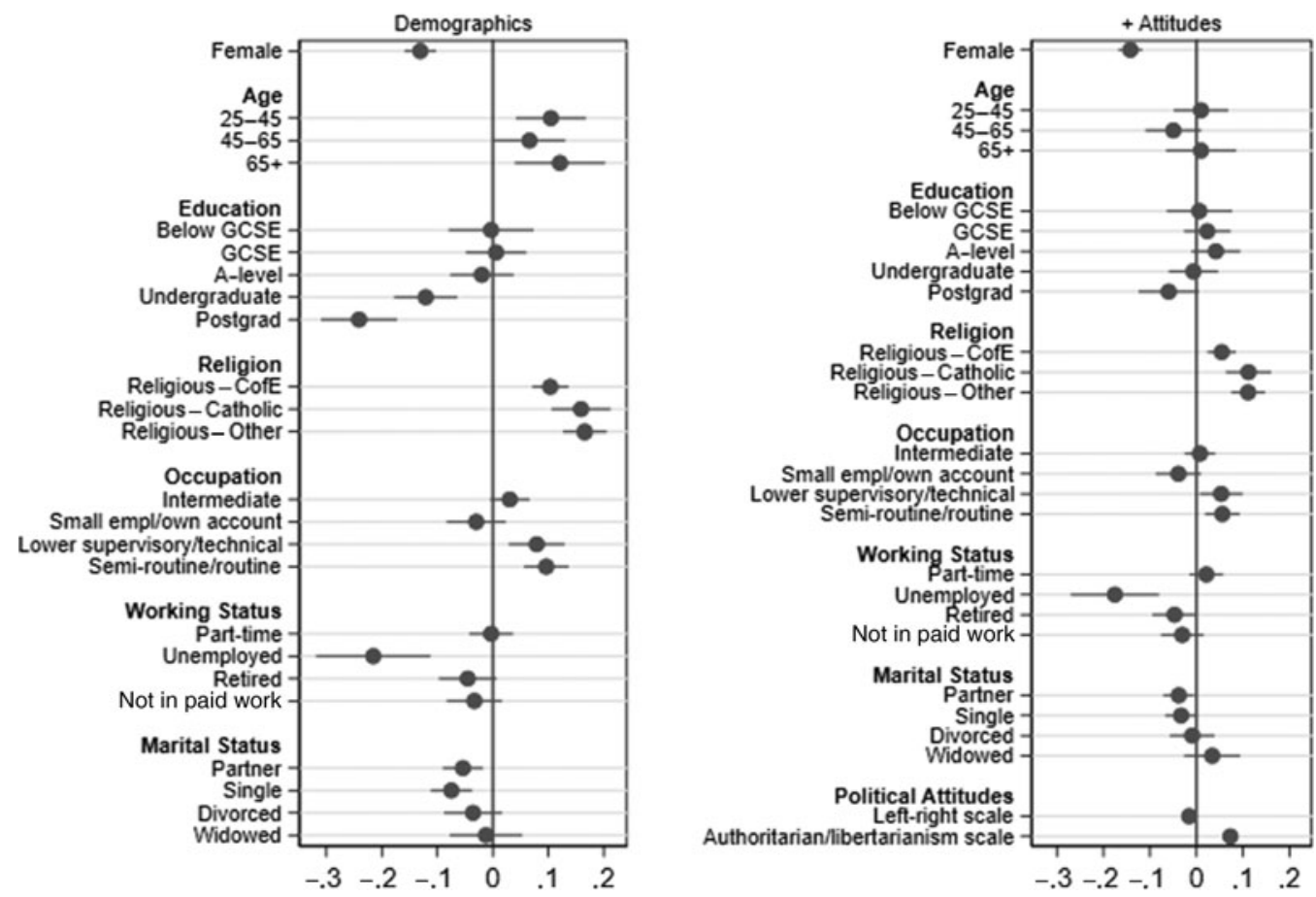

Fig. 2b. Coefficient plots from OLS regression predicting benevolent sexism (BESIP).

Notes: $N=3,108$. Data are weighted, coefficients are unstandardised and 95 per cent confidence intervals are shown.

and hierarchies, and to punish those who transgress them, and supports research that shows authoritarianism to be linked to both benevolent and hostile forms of sexism.

We do not find any clear patterns for control variables. Those in lower supervisory or technical occupations are more sexist than those in managerial or professional occupations, but this association disappears when values are controlled for. Those in routine or semi-routine professions are more likely to hold benevolent attitudes, even when controlling for political attitudes. Those who are unemployed score lower on benevolent sexism compared to those in full-time work, also controlling for values, but this is not replicated in the EPOP survey. In the BESIP survey, we further find that those that are cohabiting or are single exhibit lower levels of benevolent sexism than those who are married, but this does not hold when controlling for political values. In the EPOP survey, we find that those who are in a civil partnership are less likely to hold benevolent sexist attitudes compared to those who are married. Finally, those who are right-wing on the left-right value scale are more likely to endorse hostile sexism, while those who are more left-wing endorse benevolent sexism to a greater degree. These results are smaller in magnitude (0.01-0.02 points on a -1 to +1 scale), however, in comparison with the results for the libertarian-authoritarian scale ( 0.07 points).

In supplementary analysis, we find that gay, lesbian or bisexual respondents have statistically significantly lower scores for both hostile and benevolent sexism compared to those who identify as heterosexual, even when controlling for the attitudinal variables (see the model in the Online Supplementary Materials). This finding might reflect the more liberal ideological preferences held by lesbian, gay and bisexual people (Turnbull-Dugarte 2020). 
It should finally be noted that the US literature has identified considerable racial differences when it comes to sexism (Bracic, Israel-Trummel and Shortle 2019; Cassese and Barnes 2019; Frasure-Yokley 2018). We are unable to disaggregate by race and ethnicity due to the small sample sizes of black and minority ethnic respondents. Specifically, 86 per cent of our BESIP sample is White British and 5 per cent is Other White. Given this limitation, we suggest that our results should be interpreted as reflecting the attitudes of white British people, and indeed when we exclude the small number of black and minority ethnic respondents from the BESIP analysis, we get substantively similar results to those presented here. ${ }^{4}$ Black and minority ethnic voters could be oversampled in future electoral surveys in Britain (see Frasure-Yokley 2018) to remedy this deficiency in our analysis.

In conclusion, our most consistent findings are that: women particularly exhibit lower levels of hostile sexism; those with higher levels of education are less sexist; and religious individuals score higher on the (especially benevolent) sexism indicators. Authoritarians are more sexist, and controlling for both libertarian-authoritarian and left-right values renders the education (but not gender and religiosity) coefficients statistically insignificant.

\section{Are Sexist Attitudes Associated with British Political Behaviour?}

\section{The 2016 EU Referendum}

Next, we test the relationship between sexism and vote choice in the 2016 EU referendum (H2). We run two sets of logistic regression models predicting vote choice in the 2016 referendum, where the dependent variable is having voted Leave as opposed to Remain. The first model includes just the hostile and benevolent sexism scales, then we add controls for sociodemographics and political values. This includes several variables that were not included in the prediction of sexism models: attitudes towards immigrants; English identity; and a set of variables that measures respondents' attitudes towards equal opportunity efforts for women, gay people and black people. ${ }^{5}$ These additional variables are included because xenophobic attitudes, racism, traditionalism and attitudes related to the maintenance of social order and hierarchy have been shown to be related either to voting Leave or to voting for traditional Conservative Party options, or to correlate with sexist attitudes (Christopher and Mull 2006; Deckman and Cassese 2019; Evans and Mellon 2019; Fieldhouse et al. 2019; Schaffner 2021; 2022 Schaffner, Macwilliams and Nteta 2018; Sobolewska and Ford 2020).

To capture xenophobia, we use two measures of immigration attitudes. Respondents were presented with the statements 'Immigration is good/bad for the economy' and 'Immigration enriches/undermines cultural life.' Respondents could place themselves on a seven-point scale. To measure English identity, respondents were asked to place themselves on a seven-point scale based on their level of agreement with the statements. To capture traditionalism, racism and attitudes towards social hierarchy more generally - assuming that traditional social hierarchy is white, male and heterosexual - we used a set of questions where respondents were asked whether: 'Attempts to give equal opportunities to (black people/women/gays and lesbians) have gone too far or not far enough.' Respondents could answer on a five-point scale, ranging from 'have not gone nearly far enough' to 'have gone much too far'.

Figure 3 shows the predicted probability of voting Leave by levels of hostile and benevolent sexism for these models (regression tables are available in the Online Supplementary Materials). The top row displays the predicted probability of voting Leave at various levels of hostile sexism, with the bottom row doing so for benevolent sexism. The first column provides

\footnotetext{
${ }^{4}$ We also ran our main model with a regional variable included and found no association between a respondent's region of residence and their sexist attitudes - both these analyses are available from the authors.

${ }^{5} \mathrm{~A}$ model that excludes the women's equality variable produces the same substantive results. The correlation between this variable and hostile sexism is 0.42 and benevolent sexism is 0.14 .
} 

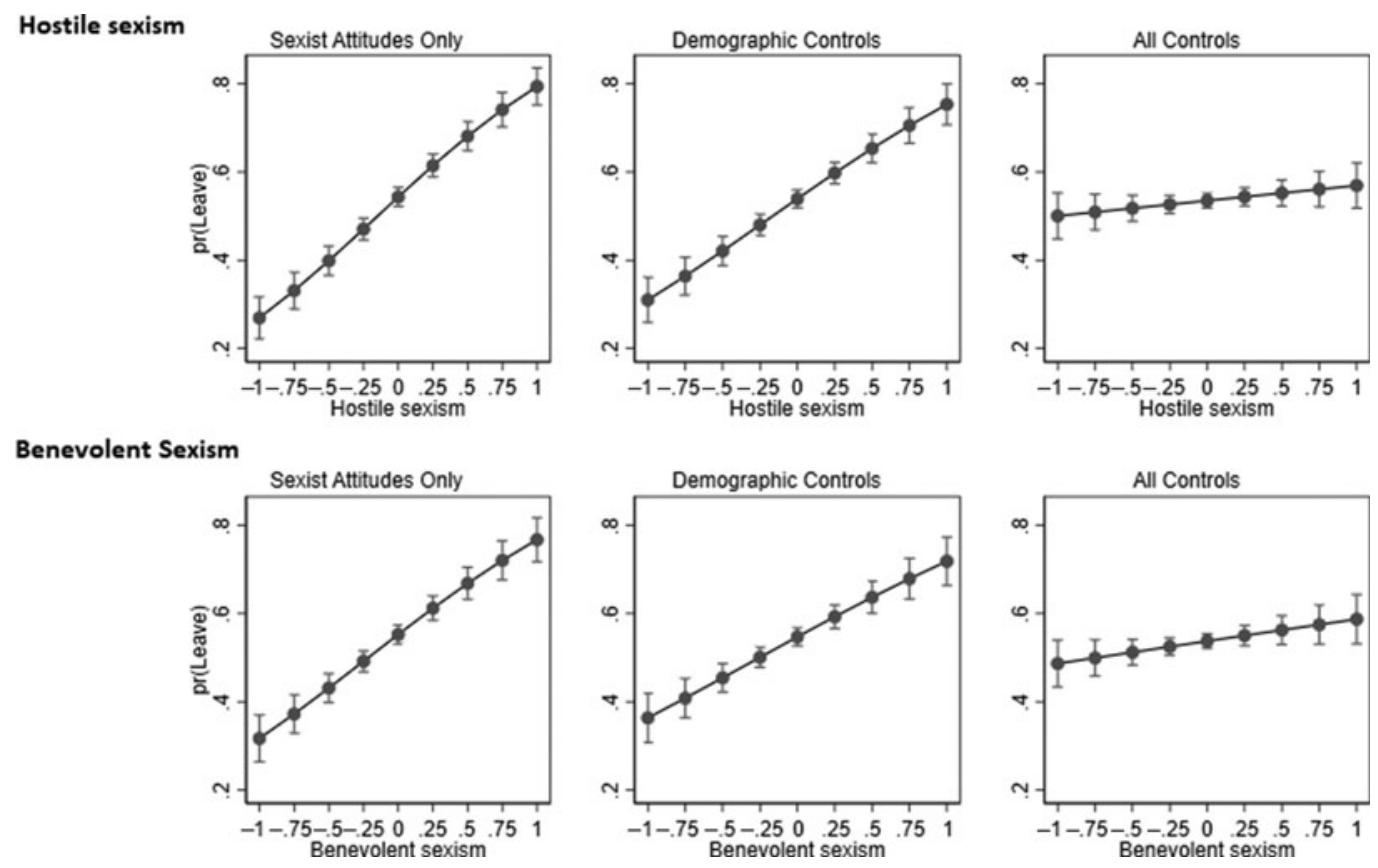

Fig. 3. Predicted likelihood voting Leave in the EU referendum at various levels of sexism (BESIP).

Notes: $N=2,433$. Predicted probabilities calculated from a logistic regression model with other variables held at their means; 95 per cent confidence intervals shown.

graphs for the model that includes sexist attitudes only; in the second column, we add a set of demographic controls; and in the last column, we add the political attitudes.

Consistent with the descriptive associations, we find a positive and statistically significant association between both hostile and benevolent sexism and Leave voting. This association holds when we include demographic controls ${ }^{6}$ - but not when we control for political attitudes. In line with other research, we find strong associations between immigration attitudes, English identity and authoritarianism variables and voting Leave in the EU referendum. We find no significant associations with the equal opportunity variables. The descriptive association between sexism and voting Leave thus does not hold after controlling for other key predictors of Leave voting.

Since our dependent variable in the previous models was measured before our attitudinal variables, we also ran the models for vote intention in a hypothetical EU referendum, rather than referendum vote in 2016. Using this dependent variable produces similar results for benevolent sexism, but stronger results for hostile sexism: the association with voting Leave in a future hypothetical referendum and hostile sexism remains even when political attitudes are included, though it becomes substantively smaller. This may suggest that sexist attitudes have become a more important political dividing line since the referendum took place in 2016.

\section{The 2019 general election}

Next, we test whether sexist attitudes are associated with voting behaviour in the 2019 general election (H3). We run multinomial logistic regression models with the outcome options Conservative, Labour, Liberal Democrat and other; non-voters are excluded. In this section, we focus on support for the Conservatives only in comparison to Labour because these are the

\footnotetext{
${ }^{6} \mathrm{We}$ also find this in the EPOP survey.
} 
parties that the vast majority of voters in 2019 endorsed. Similar to the EU referendum models, we start with a simple bivariate model of sexist attitudes and 2019 vote, and then add control variables in a stepwise manner, first for sociodemographics and then adding values and EU referendum vote. Given the continued importance of the issue of Brexit and Leave and Remain identities (Hobolt, Leeper and Tilley 2020; Sobolewska and Ford 2020), controlling for EU referendum vote is a conservative test of the relationship between sexism and vote choice because we expect EU referendum vote choice to be highly predictive of 2019 vote. The results are presented as predicted probabilities calculated from the models (shown in full in the online Supplementary Material) in Figures $4 \mathrm{a}$ and $4 \mathrm{~b}$.

We find that there is a positive association between both hostile and benevolent sexism and voting Conservative when we do not control for additional attitudes. For hostile sexism, this association remains when we control for sociodemographic characteristics, political values and even EU referendum vote choice. The relationship is also strong, with a difference of 0.10 points in the predicted probability of voting Conservative between the lowest levels of hostile sexism and the highest. Although we cannot establish causality, it is notable that individuals who are otherwise similar in terms of sociodemographic features, authoritarianism, left-right values, immigration attitudes, nationalism, attitudes towards equal the opportunities of minorities and even EU referendum vote differed in their vote choice in 2019 depending on the extent to which they endorsed hostile sexist attitudes. This shows that even in a context where gender was not a particularly salient element of the election campaign, sexist attitudes are important in understanding electoral choice in Britain. ${ }^{7}$

We do not, however, find a robust effect for a relationship between benevolent sexism and 2019 vote choice. The statistically significant relationship between benevolent sexism and vote choice remains after controlling for sociodemographics but not when controlling for political attitudes and EU referendum vote choice. $\mathrm{H} 3$ is thus partially supported: hostile, but not benevolent, sexism is associated with Conservative voting in 2019. We replicate our hostile sexism finding with the EPOP survey, but we do not find any significant associations between benevolent sexism and Conservative Party vote choice - even when excluding EU vote - when using the EPOP data. ${ }^{8}$ This suggests that the association between hostile sexism and party choice is more stable than that between benevolent sexism and party choice.

\section{Discussion and Conclusion}

Using two surveys fielding the ASI and political variables in Britain for the first time, we show that half of respondents hold some sexist attitudes, despite other surveys revealing strong support for gender egalitarianism. Sexist attitudes vary across demographic groups and value dimensions that are key to contemporary political competition in Britain, especially education level, authoritarianism and Leave-Remain identities. Endorsing hostile sexism is also associated with party support, even after controlling for other sociodemographic characteristics and values. These results indicate that sexist attitudes are politically important in Britain and relevant to political competition even in an electoral context where gender issues are not as salient as in the United States.

The Leave-Remain cleavage in the British electorate has been an important feature of the political landscape since 2016 and is heavily intertwined with the results of the 2017 and 2019 general elections (Fieldhouse et al. 2019). We show that hostile sexism in particular is associated

\footnotetext{
${ }^{7}$ The model includes respondents in England, Wales and Scotland. Results hold when the model is restricted to English respondents only.

${ }^{8}$ It should be noted that the EPOP model is run as a binary logistic regression model with the dependent variable being Conservative Party v. any other party. Due to the lower number of observations, it was not possible to run a multinomial logistic regression. In the attitudinal EPOP model, we add EU referendum vote in lieu of other political attitudes, which are not available in this dataset.
} 


\section{Hostile Sexism and 2019 GE Vote Choice}
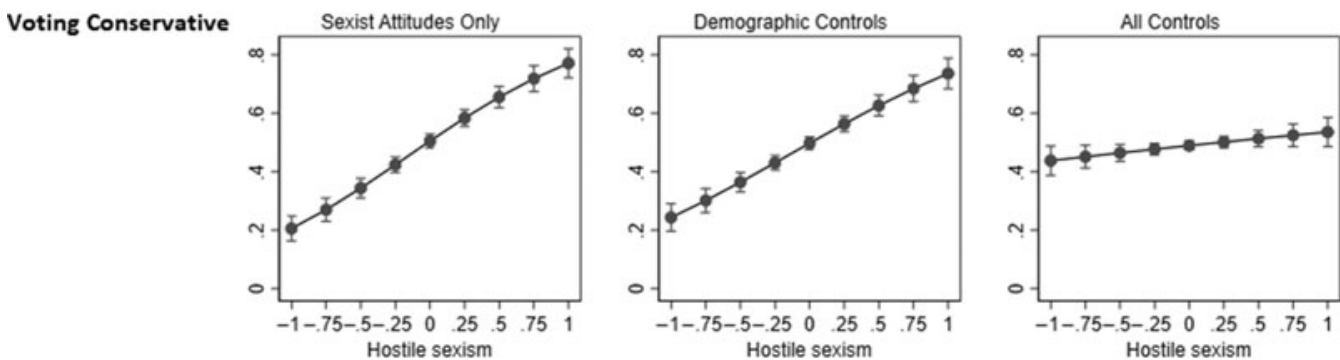

Voting Labour
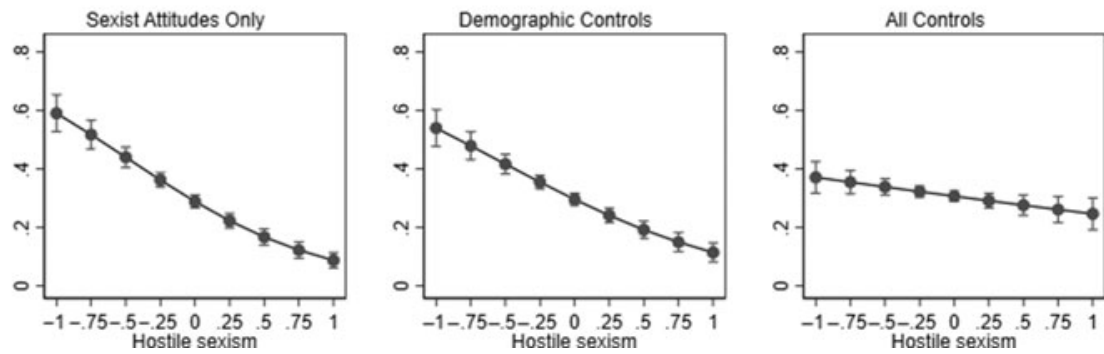

Fig. 4a. Predicted probability of voting Conservative and Labour by hostile sexism.

Notes: $N=2,295$. Predicted probabilities calculated from a multinomial logistic regression model with other variables held at their means; 95 per cent confidence intervals shown.
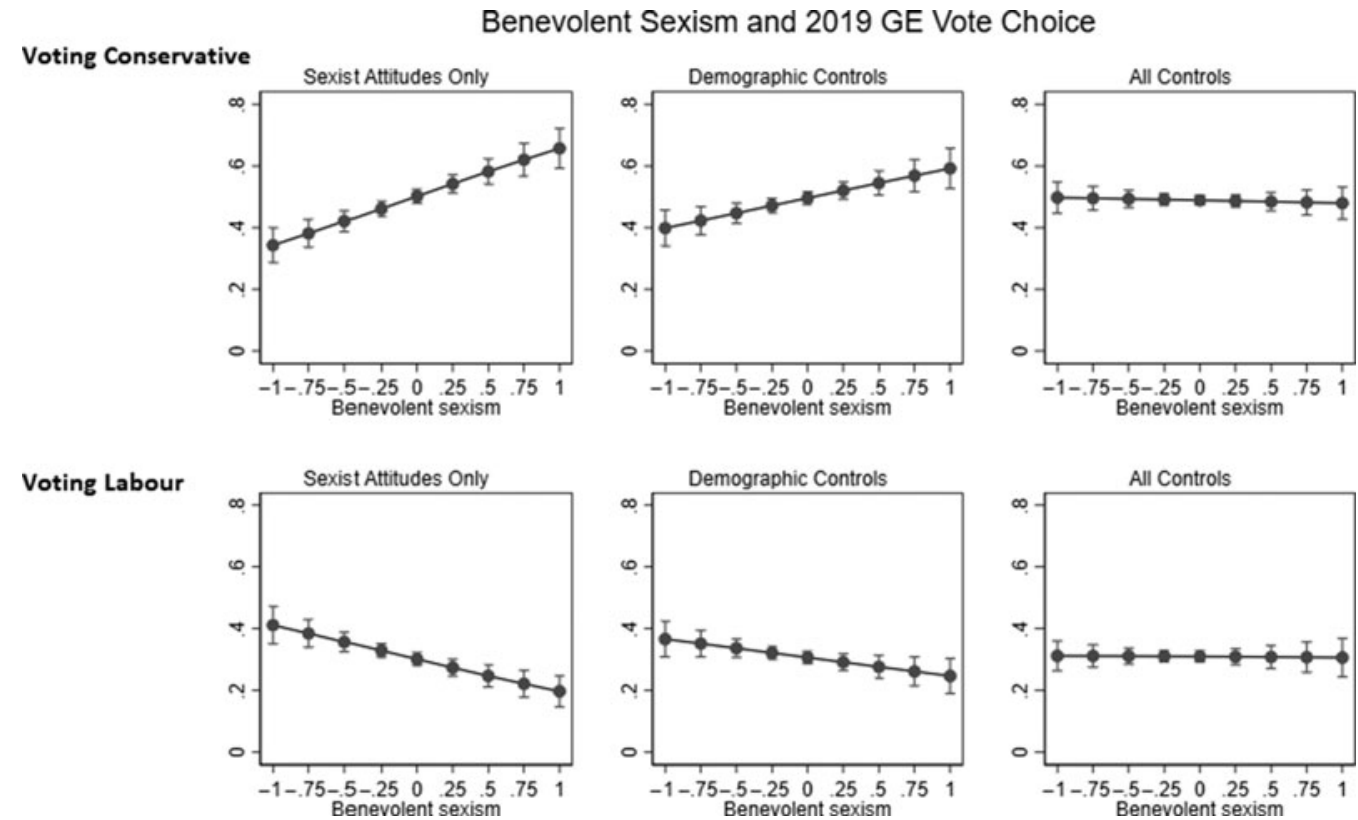

Fig. 4b. Predicted probability of voting Conservative and Labour by benevolent sexism. Notes: $N=2,295$. Predicted probabilities calculated from a multinomial logistic regression model with other variables held at their means; 95 per cent confidence intervals shown. 
with Leave voting, though this association does not hold when controlling for key political attitudes. We expected to find an association between sexism and Leave voting because of the gendered view of nationalism that was promoted during the referendum campaign. However, we find no such association. This does not mean that there was no gendered element to the referendum; Green and Shorrocks (2021) show that perceived discrimination against men does predict Leave support. We point out that although both relate to gender attitudes, perceived discrimination against men differs from hostile attitudes towards women (as measured here). Thus, although there were important gendered elements to the referendum, these should be understood more in terms of perceived discrimination against men than in terms of sexist attitudes towards women. However, it is important to note that we do find an association between hostile sexism and hypothetical referendum vote intention in 2019. This anomaly may be explained by Winter's (2010) observation that connections between masculinity/femininity and political entities develop over a period of years. It is possible that while the months-long referendum campaign was too short to allow this process to take place, the subsequent years of Brexit negotiations provided voters with the necessary time to forge gendered connections. It is notable, therefore, that we do find an association with hostile sexism and referendum vote intention, and that we consistently find that Leave voters are more sexist than Remain voters. This suggests that there is an important attitudinal division between these two political groupings when it comes to attitudes towards women, even if these attitudes did not drive the referendum vote.

Sexism is associated with party choice, with hostile sexists being especially likely to vote Conservative and less likely to vote Labour. This relationship remains once we control for sociodemographic characteristics, values, attitudes and EU referendum vote choice. While we are not claiming causality on the basis of our observational data, the relationship we identify does suggest that the association between hostile sexism and voting for right-wing/conservative parties holds outside the specific context of Trump's 2016 election. This indicates that parties could be seen as gendered in general, even if gender itself is not a highly salient element of political discourse. For example, the Labour Party's ownership of caregiving issues, as well as its high number of women MPs, may mean that voters associate it with femininity; for the same reason, sexists may reject the party. Previous scholarship (for example, Ditonto 2019; Mo 2015) has documented how sexist voters respond to candidate gender when making judgements and decisions, yet studies into voter perceptions of gendered party characteristics remain rare. Political scientists should further investigate how anthropomorphic or metaphorical - as well as literal - interpretations of gender shape political attitudes and behaviour. More broadly, the Labour and Conservative electoral coalitions are divided by sexist attitudes, indicating different priorities and motivations among their supporters.

It is notable that we do not find an association between Conservative voting and benevolent sexism given that benevolent sexism taps into traditional views about relations between men and women that we might associate with conservativism. This could be an issue with the measurement of benevolent sexism, or it could be that the antipathy element of hostile sexism makes its endorsers particularly motivated to vote for conservative options. Future research could examine these questions and consider whether the association between hostile sexism and right-wing vote choice holds in other countries, and whether it is mediated by factors such as social dominance orientation (unavailable in our data).

Like most existing studies that use the ASI as a tool to understand political attitudes and behaviours, our research focuses on a Western democracy with moderately high levels of gender equality. We believe that future political scientists should consider deploying the ASI in democracies with lower levels of gender equality, such as Ghana or India, and higher levels of gender equality, such as Denmark or Norway. Recent cross-national research (Kosakowska-Berezecka et al. 2020) has revealed that men's support for gender equality movements is lower in relatively gender-egalitarian countries, perhaps because women's progress is seen to threaten men's status. If use of the ASI reveals that sexist attitudes are indeed more politically salient in regimes with 
high levels of gender equality, this would bolster the backlash hypothesis put forward by scholars such as Inglehart and Norris (2017) and enhance our understanding of the circumstances in which gender attitudes foment political cleavages.

We also demonstrate some methodological issues that studies making use of the ASI should be aware of. The hostile sexism indicator shows a very high level of consistency in terms of its predictors of and relationship to political orientations. We find similar results across both surveys, despite using different indicators and response categories. For benevolent sexism, our results are less consistent, indicating sensitivity to the specific indicators included in the scale. We suggest that more research is required into the validity and reliability of benevolent sexism scales, as well as the specific reduced set of items that should be selected, and contend that some of the items could be increasingly irrelevant to a modern audience. Certain benevolent sexism items particularly to do with women's purity - may be losing salience in a society that is increasingly accepting of premarital sex (Park et al. 2013). By contrast, hostile sexism's items about women's sensitivity to jokes and comments, and desire to gain power over men, are likely to retain their importance in the 'Me Too' era.

We demonstrate that sexist attitudes are widespread in the British electorate and closely associated with other political cleavages. This suggests that sexism requires more attention if we are to fully understand gender attitudes and their relationship with political attitudes and behaviours. Our results make clear that the ASI provides a valuable starting point for addressing these questions.

Supplementary Material. Online appendices are available at: https://doi.org/10.1017/S0007123421000612

Data Availability Statement. Replication data for this article can be downloaded from the British Election Study (BES) website. Replication analysis files, an abridged version of the BES data and the EPOP data can be found at the BJPolS Dataverse, available at: https://doi.org/10.7910/DVN/U66LRL

Acknowledgements. We would like to thank Sarah Birch, Marco Giani and Maria Sobolewska, as well as the attendees of the University of Manchester Democracy and Elections Research Cluster seminar series, for their feedback on earlier drafts of this article. We would also like to thank the BJPolS editor and anonymous reviewers for their helpful comments. Any errors remain the authors' own.

Author Contributions. Authors are listed alphabetically; all authors contributed equally.

Financial Support. This work was supported by: the Political Studies Association Elections, Public Opinion and Parties Specialist Group; a Leverhulme Fellowship (ERM, grant number ECF-2017-081); and the Economic and Social Research Council (RdG, grant number ES/S015671/1).

Competing Interests. None.

\section{References}

Allport GW (1954) The Nature of Prejudice. Cambridge, MA: Perseus Books.

Altemeyer B (1981) Right-Wing Authoritarianism. Winnipeg: University of Manitoba Press.

Austin DEJ and Jackson M (2019) Benevolent and hostile sexism differentially predicted by facets of right-wing authoritarianism and social dominance orientation. Personality and Individual Differences 139, 34-38.

Bizumic B and Duckitt J (2018) Investigating right wing authoritarianism with a very short authoritarianism scale. Journal of Social and Political Psychology 6(1), 129-150.

Bock J, Byrd-Craven J and Burkley M (2017) The role of sexism in voting in the 2016 presidential election. Personality and Individual Differences 119, 189-193.

Bracic A, Israel-Trummel M and Shortle AF (2019) Is sexism for white people? Gender stereotypes, race, and the 2016 presidential election. Political Behavior 41(2), 281-307.

Burn SM and Busso J (2005) Ambivalent sexism, scriptural literalism, and religiosity. Psychology of Women Quarterly 29(4), 412-418.

Burns N and Gallagher K (2010) Public opinion on gender issues: the politics of equity and roles. Annual Review of Political Science 13(1), 425-443.

Campbell R (2016) Representing women voters: the role of the gender gap and the response of political parties. Party Politics 22(5), 587-597. 
Campbell R and Shorrocks R (2018) The Role of Gender-Egalitarianism in Politics from 1950 to the Present: Introducing the 'Feminist Mood'. Paper presented at the Annual Meeting of the American Political Science Association, Boston, MA, 30 August-2 September.

Cassese EC and Barnes TD (2019) Reconciling sexism and women's support for Republican candidates: a look at gender, class, and whiteness in the 2012 and 2016 presidential races. Political Behavior 41(3), 677-700.

Cassese EC and Holman MR (2019) Playing the woman card: ambivalent sexism in the 2016 US presidential race. Political Psychology, 40(1), 55-74.

Christopher AN and Mull MS (2006) Conservative ideology and ambivalent sexism. Psychology of Women Quarterly 30(2), 223-230.

Deckman M and Cassese E (2019) Gendered nationalism and the 2016 US presidential election: how party, class, and beliefs about masculinity shaped voting behavior. Politics \& Gender 17(2), 1-24, https://oi.org/10.1017/S1743923X19000485

Ditonto T (2019) Direct and indirect effects of prejudice: sexism, information, and voting behavior in political campaigns. Politics, Groups, and Identities 7(3), 590-609.

Duckitt J et al. (2010) A tripartite approach to right-wing authoritarianism: the authoritarianism-conservatism-traditionalism model. Political Psychology 31(5), 685-715.

De Geus R, Ralph-Morrow E and Shorrocks R (2021) Replication Data for: Understanding Ambivalent Sexism and its Relationship with Electoral Choice in Britain; https://doi.org/10.7910/DVN/U66LRL

Edwards M and Schaffner B (2020) Sexism among American adults. Contexts 19(4), 72-74.

Evans G and Mellon J (2019) Immigration, Euroscepticism, and the rise and fall of UKIP. Party Politics 25(1), 76-87.

Fieldhouse E et al. (2019) Electoral Shocks: The Volatile Voter in a Turbulent World. Oxford: Oxford University Press.

Fieldhouse E et al. (2020) British Election Study Internet Panel Wave 19. Available at: https://www.britishelectionstudy.com/ data-object/wave-19-of-the-2014-2023-british-election-study-internet-panel/.

Frasure-Yokley L (2018) Choosing the velvet glove: women voters, ambivalent sexism, and vote choice in 2016. The Journal of Race, Ethnicity, and Politics 3(1), 3-25.

Garaigordobil $\mathbf{M}$ and Aliri J (2013) Ambivalent Sexism Inventory: standardization and normative data in a sample of the Basque Country. Behavioral Psychology/Psicologia Conductual 21(1), 173-186.

Gaunt R (2012) 'Blessed is he who has not made me a woman': ambivalent sexism and Jewish religiosity. Sex Roles 67, 477-487.

Glick P and Fiske ST (1996) The Ambivalent Sexism Inventory: differentiating hostile and benevolent sexism. Journal of Personality and Social Psychology 70(3), 491-512.

Glick P and Fiske ST (1997) Hostile and benevolent sexism: measuring ambivalent sexist attitudes toward women. Psychology of Women Quarterly 21(1), 119-135.

Glick P and Fiske ST (2001) An ambivalent alliance: hostile and benevolent sexism as complementary justifications for gender inequality. American Psychologist 56(2), 109-118.

Glick P, Lameiras M and Castro YR (2002) Education and Catholic religiosity as predictors of hostile and benevolent sexism toward women and men. Sex Roles 47, 433-441.

Glick P et al. (2000) Beyond prejudice as simple antipathy: hostile and benevolent sexism across cultures. Journal of Personality and Social Psychology 79(5), 763-775.

Gove M (2016) Statement from Michael Gove MP, Secretary of State for Justice, on the EU Referendum. Available from http://www.voteleavetakecontrol.org/statement_from_michael_gove_mp_secretary_of_state_for_justice_on_the_eu_referendum.html

Green J and Shorrocks R (2021) The gender backlash in the vote for Brexit. Political Behavior. Available from https://doi.org/ 10.1007/s11109-021-09704-y

Hellmer K, Stenson JT and Jylhä KM (2018) What's (not) underpinning ambivalent sexism? Revisiting the roles of ideology, religiosity, personality, demographics, and men's facial hair in explaining hostile and benevolent sexism. Personality and Individual Differences 122, 29-37.

Hobolt SB, Leeper TJ and Tilley J (2020) Divided by the vote: affective polarization in the wake of the Brexit referendum. British Journal of Political Science 51(4), 1476-1493. https://doi.org/10.1017/S0007123420000125

Inglehart $\mathbf{R}$ and Norris $\mathbf{P}$ (2017) Trump and the populist authoritarian parties: the Silent Revolution in reverse. Perspectives on Politics 15(2), 443-454.

Johnson B (2016) Boris Johnson Exclusive: There Is Only One Way to Get the Change We Want - Vote to Leave the EU. Available from https://www.telegraph.co.uk/opinion/2016/03/16/boris-johnson-exclusive-there-is-only-one-way-to-getthe-change/

Kosakowska-Berezecka $\mathbf{N}$ et al. (2020) Country-level and individual-level predictors of men's support for gender equality in 42 countries. European Journal of Social Psychology 50, 1276-1291.

Mo CH (2015) The consequences of explicit and implicit gender attitudes and candidate quality in the calculations of voters. Political Behavior 37, 357-395.

Park A et al. (2013) British Social Attitudes: The 30th Report. London: The National Centre for Social Research.

Phillips D et al. (2018) British Social Attitudes: The 35th Report. London: The National Centre for Social Research.

Prosser C (2020) The end of the EU affair: the UK general election of 2019. West European Politics 44(2), 450-461. 
Ratliff KA et al. (2017) Engendering support: hostile sexism predicts voting for Donald Trump over Hillary Clinton in the 2016 U.S. presidential election. Group Processes \& Intergroup Relations 22(4), 578-593.

Schaffner B (2021) Optimizing the measurement of sexism in political surveys. Political Analysis. Available from http://www. doi.org/10.1017/pan.2021.6

Schaffner B (2022) The heightened importance of racism and sexism in the 2018 US midterm elections. British Journal of Political Science 52(1), 493-500.

Schaffner BF, Macwilliams M and Nteta T (2018) Understanding white polarization in the 2016 vote for president: the sobering role of racism and sexism. Political Science Quarterly 133(1), 9-34.

Schrock D and Schwalbe M (2009) Men, masculinity, and manhood acts. Annual Review of Sociology 35(1), 277-295.

Shorrocks R (2018) A feminist generation? Cohort change in gender-role attitudes and the second-wave feminist movement. International Journal of Public Opinion Research 30(1), 125-145.

Sibley CG, Wilson MS and Duckitt J (2007) Antecedents of men's hostile and benevolent sexism: the dual roles of social dominance orientation and right-wing authoritarianism. Personality and Social Psychology Bulletin 33(2), 160-172.

Sobolewska M and Ford R (2020) Brexitland: Identity, Diversity and the Reshaping of British Politics. Cambridge: Cambridge University Press.

Turnbull-Dugarte SJ (2020) The European lavender vote: sexuality, ideology and vote choice in Western Europe. European Journal of Political Research 59(3), 517-537.

Winter NJG (2010) Masculine Republicans and feminine Democrats: gender and Americans' explicit and implicit images of the political parties. Political Behavior 32, 587-618.

Winter NJG (2018) The Two Faces of Sexism: Hostility, Benevolence, and American Elections. Paper presented at the Annual Meeting of the American Political Science Association, Boston, MA, 30 August-2 September.

YouGov (2019) Best Party on Issues. Available from https://d25d2506sfb94s.cloudfront.net/cumulus_uploads/document/ h1webgz4u8/YG\%20Trackers\%20-\%20Best\%20Party\%20On\%20Issues.pdf

Cite this article: de Geus R, Ralph-Morrow E, Shorrocks R (2022). Understanding Ambivalent Sexism and its Relationship with Electoral Choice in Britain. British Journal of Political Science 52, 1564-1583. https://doi.org/10.1017/ S0007123421000612 